mat. nauk [Issues of numerical implementation of the method consistent perturbation parameters when calculating shell designs : Dr. phys. and math. sci. diss.]. Saratov, 2005. (in Russian).

5. Kuznecov V. N. Metod posledovatel'nogo vozmushcheniia parametrov $v$ prilozhenii $k$ raschetu dinamicheskoi ustoichivosti tonkostennykh obolochechnykh konstruktsii : Diss. kand. tehn. nauk [The method of successive perturbations of the parameters in the application to the calculation of dynamic stability of thinwalled shell structures : Dr. techn. sci. diss.]. Saratov, 2000 (in Russian).

6. Bessonov L. V. Chislennaia realizatsiia algoritma spektral'nogo kriteriia lokal'noi poteri ustoichivosti obolochechnoi konstruktsi [Numerical realization of algorithm of spectral criterion of local buckling of shell structures]. Issledovaniia po algebre, teorii chisel, funktsional'nomu analizu i smezhnym voprosam : mezhouz. sb. nauch. tr. [Research in algebra, number theory, functional analysis and related issues : interuniversity collection of scientific papers], Saratov, Saratov Univ Press, 2012, iss. 7, pp. 3-9.

7. Pisarenko G. S., Jakovlev A. P., Matveev V. V. Spravochnik po soprotivleniiu materialov [The reference resistance of materials]. Kiev, Naukova dumka, 1988, $734 \mathrm{p}$.

\title{
ON WEAK DISCONTINUITIES AND JUMP EQUATIONS ON WAVE SURFACES IN MICROPOLAR THERMOELASTIC CONTINUA
}

\begin{abstract}
V. A. Kovalev ${ }^{1}$, E. V. Murashkin ${ }^{2}$, Yu. N. Radayev ${ }^{3}$
${ }^{1}$ Moscow City Government University of Management Moscow, 28, Sretenka str., 107045, Moscow, Russia, vlad_koval@mail.ru ${ }^{2}$ National Research Nuclear University MEPhl (Moscow Engineering Physics Institute), 31, Kashirskoe shosse, 115409, Moscow, Russia, murashkin@ipmnet.ru, evmurashkin@gmail.com

${ }^{3}$ Institute for Problems in Mechanics of RAS, 101-1, Vernadskogo ave., 119526, Moscow, Russia, murashkin@ipmnet.ru, evmurashkin@gmail.com, radayev@ipmnet.ru, y.radayev@gmail.com

The present study is devoted to problem of propagating surfaces of weak and strong discontinuities of translational displacements, microrotations and temperature in micropolar (MP) thermoelastic (TE) continua. Problems of propagation of weak discontinuities in type-I MPTE continua are discussed. Geometrical and kinematical compatibility conditions due to Hadamard and Thomas are used to study possible wave surfaces of weak discontinuities. Weak discontinuities are discriminated according to spatial orientations of the discontinuities polarization vectors (DPVs). It is shown that the surfaces of weak discontinuities can propagate exist without weak discontinuities of the temperature field. Second part of the paper is concerned the discussions of the propagating surfaces of strong discontinuities of field variables in type-II MPTE continua. Constitutive relations for hyperbolic thermoelastic type-II micropolar continuum is derived by the field theory. The special form of the first variation of the action integral is used in order to obtained 4-covariant jump conditions on wave surfaces. Three-dimensional form of the jump conditions on the surface of a strong discontinuity of thermoelastic field are derived from 4-covariant form.
\end{abstract}

Key words: micropolar thermoelasticity, type-I continuum, type-II continuum, weak discontinuity, strong discontinuity, shock wave, Iongitudinal wave, transverse wave, compatibility condition, jump.

\section{PRELIMINARY REMARKS}

Problems of micropolar continua take its origin from the classical E. and F. Cosserat's paper [1]. Micropolar (MP) continuum theories include not only translational displacements but also additional degrees of freedom. These degrees of freedom are coupled with changes in reper (three directors) associated with microvolume. Such changes may be described by a rotation vector when reper associated with microvolume are rigid rotated. In contrary to conventional elasticity a continuum with microstucture is described by the asymmetric strain and stress tensors known from many previous discussions. Thus the asymmetric elastic theory is characterized by a comparatively large number of constitutive elastic constants need to be determined from the experimental observations. There are several phenomena (for example, the anomalous piezoelectric effect in quartz, the dispersion of elastic waves, as well as a number of other experimentally observed elastic properties of the pure crystals) being beyond the scope of the conventional thermoelasticity (CTE) and piezoelectroelasticity. That is why a development of complex theories seems to be actual.

The type-I micropolar thermoelastic (MPTE-I) continuum may be described in terms of field formalism, for example, from positions of the Green-Naghdi thermoelasticity (GN-theory). Now such mathematical frameworks of the thermoelastic behavior of solids are rapidly refined $[2,3]$. They are based on different modifications of the classical Fourier law of heat conduction. The refinements aim at derivations of hyperbolic partial differential equations of coupled thermoelasticity. Those are to 
simultaneously fulfill the following conditions: 1.) Finiteness of the heat signal propagation velocity, and 2.) The ability of the spatial propagation of the thermoelastic waves without attenuation, and 3.) Existence of distortionless wave forms akin to the classical d'Alembert type waves. GN-thermoelasticity theory itself can be subdivided into the three different types. Type-I theory (GNI/CTE thermoelasticity) is based on the classical Fourier law of heat conduction with an infinite velocity of propagation of an exponentially decaying heat signal. Type-II theory (GNII, hyperbolic thermoelasticity) is characterised by the energy conservation and the finite propagation velocity of thermal waves known as second sound waves.

In-depth study of plane harmonic type-I thermoelastic waves is given in [4]. It is shown that dispersion equation has exactly two complex wavenumbers for a given frequency. Moreover their real and imaginary parts are strictly positive. Plane waves in type-II continua are studied in [5]. Plane thermoelastic wave or second sound wave is characterized by four real wavenumbers. Two of them are strictly positive. In [6] problems concerning plane harmonic wavenumbers of coupled type-III thermoelastic waves are discussed. In all studies [4-6] the linear symmetrical thermoelasticity is employed. They are summarized in the monograph [7].

The present study is devoted to problem of propagating surfaces of weak and strong discontinuities of translational displacements, microrotations and temperature in micropolar (MP) thermoelastic (TE) continua. In first part of the paper is discussed the problems of the propagation of weak discontinuities in type-I MPTE continua. After preliminary remarks (Sec. 1) in Sec. 2 the requisite equations for type-I linear micropolar thermoelastic continuum are considered. Those includes the equation of motion, conservation energy principle and entropy balance equations.

In Sec. 3 compatibility conditions for weak discontinuities propagation surfaces of displacements, microrotations and temperature in the type-I micropolar thermoelastic continuum are given. These conditions are derived from the requisite equations (Sec. 2) and the geometrical and kinematical conditions due to Hadamard and Thomas [8]. The admissible normal velocities of the propagating surfaces of weak discontinuities are found.

In Sec. 4 the distinguished cases of propagating wave surfaces in MPTE-I continuum are separately considered. Propagating surfaces of weak discontinuities are discriminated depending on the spatial orientations of DPVs.

In Sec. 5 the constitutive equations for hyperbolic thermoelastic type-II micropolar continuum is derived by the field theory. The special form of the first variation of the action integral is used in order to obtained 4-covariant jump conditions on wave surfaces.

In Sec. 6 the problems of the propagating surfaces of strong discontinuities of field variables in type-II MPTE continua are considered. Three-dimensional form of the jump conditions on the surface of a strong discontinuity of thermoelastic field are derived from 4-covariant form.

\section{REMINDER OF BASIC EQUATIONS OF MPTE-I CONTINUUM}

A framework of MPTE-I continuum (see [9] for details) is used throughout the paper. Such continua permit the existence of rotational degrees of freedom (a rotation vector $\phi$ ) along with translational degrees of freedom (the translational displacement vector $\mathbf{u}$ ). For MPTE-I continuum, equations of motion of micropolar medium are written in direct tensor representation for the case of the absence of mass forces and mass moments

$$
\left\{\begin{array}{l}
\nabla \cdot \sigma=\rho \ddot{u}, \\
\nabla \cdot m+\epsilon \cdot \sigma=\mathfrak{J} \ddot{\phi},
\end{array}\right.
$$

where $\boldsymbol{\rho}$ is the mass density tensor, $\mathfrak{J}$ is a tensor of inertia, $\boldsymbol{\epsilon}$ is the three-dimensional Levi-Civita symbol (permutation symbol, antisymmetric symbol, or alternating symbol), $\nabla$ is the three-dimensional Hamiltonian differential operator (the nabla symbol), dot over a symbol denotes partial differentiation with respect to time at fixed spatial coordinates. For $\boldsymbol{\rho}$ and $\mathfrak{J}$ tensors the symmetry conditions $\rho_{i j}=\rho_{j i}$, $\mathfrak{J}_{i j}=\mathfrak{J}_{j i}$ are obviously valid. where. Another form of the tensor representation of equations (1) is (see [10])

$$
\left\{\begin{array}{l}
\nabla \cdot \sigma=\rho \ddot{\mathbf{u}}, \\
\nabla \cdot \boldsymbol{m}+\boldsymbol{\sigma} \times \underline{\mathbf{I}}=\mathfrak{J} \ddot{\phi},
\end{array}\right.
$$

wherein $\mathbf{I}$ is the second-order unit tensor. 
Equations (1) and (2) in rectangular co-ordinate system can be deduced in form

$$
\left\{\begin{array}{l}
\partial_{j} \sigma_{j i}=\rho_{i j} \ddot{u}_{j} \\
\partial_{j} m_{j i}+\epsilon_{i j k} \sigma_{j k}=\mathfrak{J}_{i j} \ddot{\phi}_{j}
\end{array}\right.
$$

where $\partial_{j}$ is partial derivative on spatial coordinate $x_{j}$.

If the equation of entropy balance are taken in form

$$
\dot{s}=\xi-\nabla \cdot\left(\frac{\mathbf{h}}{\theta}\right),
$$

where $s$ denotes the entropy referred to the unit of volume, $\mathbf{h}$ is the heat flux vector, $\theta$ is the actual temperature, $\xi$ denotes the internal entropy product, then the equations of energy balance may be written as

$$
\dot{\psi}=\operatorname{tr}(\boldsymbol{\sigma} \cdot \dot{\boldsymbol{e}})+\operatorname{tr}(\boldsymbol{m} \cdot \dot{\boldsymbol{\Gamma}})-s \dot{\theta}-\theta\left(\mathbf{h} \cdot \frac{\boldsymbol{\nabla} \theta}{\theta^{2}}-\xi\right),
$$

where $\psi$ is the free energy per unit of volume.

The asymmetric strain tensor $e$ and bending-torsion tensor $\Gamma$ are associated with translational displacements $\mathbf{u}$ and microrotations $\phi$ by formulae

$$
e=\nabla \otimes \mathbf{u}-\epsilon \cdot \phi, \quad \Gamma=\nabla \otimes \phi .
$$

The equation (5) are represented in a rectangular co-ordinate system as

$$
e_{j i}=\partial_{j} u_{i}-\epsilon_{j i k} \phi_{k}, \quad \Gamma_{j i}=\partial_{j} \phi_{i} .
$$

Since the free energy $\psi=\psi(\boldsymbol{e}, \boldsymbol{\Gamma}, \theta)$ is the function of the independent variables $\boldsymbol{e}, \boldsymbol{\Gamma}, \theta$ then

$$
\dot{\psi}=\frac{\partial \psi}{\partial e_{j i}} \dot{e}_{j i}+\frac{\partial \psi}{\partial \Gamma_{j i}} \dot{\Gamma}_{j i}+\frac{\partial \psi}{\partial \theta} \dot{\theta}
$$

Therefore the following equations can be obtained from the comparison of equations (4) and (6)

$$
\sigma_{j i}=\frac{\partial \psi}{\partial e_{j i}}, \quad \mu_{j i}=\frac{\partial \psi}{\partial \Gamma_{j i}}, \quad s=-\frac{\partial \psi}{\partial \theta}, \quad \xi+\mathbf{h} \cdot \frac{\boldsymbol{\nabla} \theta}{\theta^{2}}=0 .
$$

The second law of thermodynamics is correct when the $\xi \geqslant 0$. Whence the Clausius - Duhem inequality can be written in form

$$
-\mathbf{h} \cdot \frac{\nabla \theta}{\theta^{2}} \geqslant 0 \text {. }
$$

The inequality (8) is satisfied by using the Fourier's law of heat conduction, which states the proportionality of the heat flux vector $\mathbf{h}$ and negative spatial temperature gradient $\theta$

$$
\mathbf{h}=-\boldsymbol{\Lambda} \cdot \nabla \theta
$$

where $\boldsymbol{\Lambda}$ is the material thermal conductivity tensor (thermal diffusion tensor). $\boldsymbol{\Lambda}$ is a positive definite matrix.

The equation (3) and takin into account the equations (7) and (9) may be transformed as

$$
\dot{s} \theta=-\nabla \cdot \mathbf{h}=\boldsymbol{\nabla} \cdot \boldsymbol{\Lambda} \cdot \nabla \theta .
$$

Let us expand the free energy $\psi$ into the Taylor series in the vicinity of the natural state $\boldsymbol{e}=\boldsymbol{\Gamma}=\mathbf{0}$, $\theta=0$, disregarding the terms of higher order than the second one. The following form of the expansion is obtained for isotropic, homogeneous and centrosymmetric bodies

$$
\begin{aligned}
\psi=\frac{\mu+\eta}{2} e_{j i} e_{j i}+ & \frac{\mu-\eta}{2} e_{j i} e_{i j}+\frac{\lambda}{2} e_{k k} e_{n n}+\frac{\gamma+\varepsilon}{2} \Gamma_{j i} \Gamma_{j i}+\frac{\gamma-\varepsilon}{2} \Gamma_{j i} \Gamma_{i j}+ \\
& +\frac{\beta}{2} \Gamma_{k k} \Gamma_{n n}-\alpha e_{k k} \theta-\varsigma \Gamma_{k k} \theta-\frac{\Lambda_{*}}{2} \theta^{2} .
\end{aligned}
$$


The constitutive equations of MPTE-I continuum can be derived according to equations (7)

$$
\begin{gathered}
\boldsymbol{\sigma}=(\mu+\eta) \boldsymbol{e}+(\mu-\eta) \boldsymbol{e}^{\mathrm{T}}+(\lambda \operatorname{tr} \boldsymbol{e}-\alpha \theta) \mathbf{I} \\
\boldsymbol{m}=(\gamma+\varepsilon) \boldsymbol{\Gamma}+(\gamma-\varepsilon) \boldsymbol{\Gamma}^{\mathrm{T}}+(\beta \operatorname{tr} \boldsymbol{\Gamma}-\varsigma \theta) \mathbf{I}, \\
s=\alpha \operatorname{tr} \boldsymbol{e}+\varsigma \operatorname{tr} \boldsymbol{\Gamma}+\Lambda_{*} \theta
\end{gathered}
$$

wherein $\lambda, \mu, \eta, \gamma, \beta, \varepsilon$ are isothermal constitutive constants of type-I micropolar thermoelastic continuum; $\alpha, \varsigma$ are constitutive constants providing coupling of equations of motion and heat conduction. Constants $\alpha, \varsigma$ depend not only on the mechanical properties of the continuum, but also depend on the thermal properties.

Rewrite (11) as follows

$$
\begin{gathered}
\sigma_{i j}=(\mu+\eta) e_{j i}+(\mu-\eta) e_{i j}+\left(\lambda \operatorname{tr} e_{k k}-\alpha \theta\right) \delta_{i j}, \\
m_{i j}=(\gamma+\varepsilon) \Gamma_{j i}+(\gamma-\varepsilon) \Gamma_{i j}+\left(\beta \operatorname{tr} \Gamma_{k k}-\varsigma \theta\right) \delta_{i j}, \\
s=\alpha e_{k k}+\varsigma \Gamma_{k k}+\Lambda_{*} \theta .
\end{gathered}
$$

Note that

$$
\left(\frac{\partial s}{\partial \theta}\right)_{\Gamma, e}=\frac{\kappa}{\theta}
$$

where $\kappa$ is the heat capacity (per unit volume) at constant (zero) strains. Thus the equation is derived

$$
d s=\alpha d \operatorname{tr} e+\varsigma d \operatorname{tr} \boldsymbol{\Gamma}+\frac{\kappa}{\theta} d \theta .
$$

Integrating this equation for entropy in assumption that $s=0$ for natural state is obtained

$$
s=\alpha \operatorname{tr} e+\varsigma \operatorname{tr} \Gamma+\kappa \ln \left(\frac{\theta}{T_{0}}\right) .
$$

Expand the logarithm in (12) under condition of $\left|\theta / T_{0}\right| \ll 1$ allows rewrite entropy equation in form

$$
s=\alpha \operatorname{tr} e+s \operatorname{tr} \boldsymbol{\Gamma}+\frac{\kappa}{T_{0}} \theta .
$$

Consequently the heat conduction equation can be derived by transforming equations (10) and (13) as

$$
\boldsymbol{\nabla} \cdot \boldsymbol{\Lambda} \cdot \nabla \theta-\kappa \dot{\theta}-\alpha \boldsymbol{\nabla} \cdot \dot{\mathbf{u}}-\varsigma \nabla \cdot \dot{\phi}=0 .
$$

After substituting the stress tensors $\boldsymbol{\sigma}$ and $\boldsymbol{m}$ from the formulas (11) in the equations of motion (1) and taking account of (5) the system of coupled partial differential equations of motion and heat conduction for a linear isotropic type-I micropolar thermoelastic continuum in the absence of mass forces, moments, and heat sources can be written as $[9,11]$ :

$$
\left\{\begin{array}{l}
(\lambda+\mu-\eta) \nabla \boldsymbol{\nabla} \cdot \mathbf{u}+(\mu+\eta) \boldsymbol{\nabla} \cdot \boldsymbol{\nabla} \mathbf{u}+2 \eta \boldsymbol{\nabla} \times \boldsymbol{\phi}-\alpha \boldsymbol{\nabla} \theta-\rho \ddot{\mathbf{u}}=\mathbf{0}, \\
(\beta+\gamma-\varepsilon) \boldsymbol{\nabla} \cdot \boldsymbol{\phi}+(\gamma+\varepsilon) \boldsymbol{\nabla} \cdot \boldsymbol{\nabla} \boldsymbol{\phi}-4 \eta \boldsymbol{\phi}+2 \eta \boldsymbol{\nabla} \times \mathbf{u}-\varsigma \boldsymbol{\nabla} \theta-\mathfrak{J} \ddot{\phi}=\mathbf{0}, \\
\boldsymbol{\nabla}^{2} \theta-\frac{\kappa}{\Lambda_{*}} \dot{\theta}-\frac{\alpha}{\Lambda_{*}} \boldsymbol{\nabla} \cdot \dot{\mathbf{u}}-\frac{\varsigma}{\Lambda_{*}} \boldsymbol{\nabla} \cdot \dot{\boldsymbol{\phi}}=0 .
\end{array}\right.
$$

Hereafter $\theta$ is the temperature increment over the referential temperature, $\kappa$ is the heat capacity (per unit volume) at constant (zero) strains.

As pointed out the nonzero constitutive constants $\alpha, \varsigma$ provide coupling of micropolar thermoelasticity equations. It is usually assumed that $\varsigma=0$ (see [9]). This constitutive constant is kept in all further considerations for the completeness analysis .

The scalar equation in the system (14) is called a generalized heat conduction equation conjugate to the equations of motion (the first and the second equations in (14)). 


\section{PROPAGATING WEAK DISCONTINUITIES OF THERMOMECHANICAL FIELDS IN MPTE-I CONTINUUM}

This section is devoted to processes of propagating weak discontinuities of translational displacements $\mathbf{u}$, microrotations $\phi$ and temperature $\theta$ in the MPTE-I continuum. System of partial differential equations (14) includes partial derivative order not higher than the second. Let a wavefront (wave surface $\Sigma$ ) of weak discontinuities displacements $\mathbf{u}$, microrotations $\phi$ and temperature $\theta$ be propagated in three-dimensional space with normal velocity $G$. Unit normal vector to that wave surface is denoted by $\mathbf{n}$. If surface $\Sigma$ is parameterized by

$$
x^{i}=\psi^{i}\left(y^{1}, y^{2}, t\right)
$$

then components of first $g^{\alpha \beta}$ and second $b_{\alpha \beta}$ fundamental forms of surface $\Sigma$ are computed by formulas

$$
g_{\alpha \beta}=\frac{\partial \psi^{i}}{\partial y^{\alpha}} \frac{\partial \psi^{i}}{\partial y^{\beta}}=\partial_{\alpha^{\prime}} x^{i} \partial_{\beta^{\prime}} x^{i}, \quad b_{\alpha \beta}=\frac{\partial^{2} \psi^{i}}{\partial y^{\alpha} \partial y^{\beta}} n^{i}=\partial_{\alpha^{\prime}} \partial_{\beta^{\prime}} x^{i} n^{i}, \quad \partial_{\alpha} n^{i}=-g^{\beta \gamma} b_{\beta \alpha} \partial_{\gamma^{\prime}} x^{i} .
$$

Kinematical and geometrical compatibility conditions of the second and the first order due to Hadamard and Thomas valid for an arbitrary physical field $\varphi$ read

$$
\begin{gathered}
\llbracket \partial_{i} \partial_{j} \varphi \rrbracket=D n_{i} n_{j}+g^{\alpha \beta} \partial_{\alpha^{\prime}} C\left(n_{i} \partial_{\beta^{\prime}} x_{j}+n_{j} \partial_{\beta^{\prime}} x_{i}\right)-g^{\alpha \beta} g^{\sigma \tau} C b_{\alpha \sigma} \partial_{\beta^{\prime}} x_{i} \partial_{\tau^{\prime}} x_{j}, \\
\llbracket \partial_{i} \dot{\varphi} \rrbracket=\left(-D^{k} G+\delta_{4} C\right) n_{i}+g^{\alpha \beta} \partial_{\alpha^{\prime}}(C G) \partial_{\beta^{\prime}} x_{i}, \\
\llbracket \ddot{\varphi} \rrbracket=\left(D G^{2}-\delta_{4} C\right) G+C \delta_{4} G, \quad \llbracket \partial_{4} \varphi \rrbracket=-C G, \quad \llbracket \partial_{i} \varphi \rrbracket=C n_{i},
\end{gathered}
$$

where $i, j=1,2,3 ; \alpha, \beta, \tau, \sigma=1,2$; the prime in superscripts are denoted by the Greek indices related to surface Gaussian coordinates; $D=\llbracket \partial_{i} \partial_{j} \varphi \rrbracket n^{i} n^{j} ; \delta_{4}$ is the delta-derivative operator, $\llbracket \cdot \rrbracket$ denote 3 -jumps of the field variables..

If, in particular, the first derivative of the function $\varphi$ is continuous across the surface $\Sigma$ the relations (15) can be reduced to

$$
\llbracket \partial_{i} \partial_{j} \varphi \rrbracket=D n_{i} n_{j}, \quad \llbracket \partial_{i} \dot{\varphi} \rrbracket=-D G n_{i}, \quad \llbracket \ddot{\varphi} \rrbracket=D G^{2} .
$$

The obtained expressions are easy to rewrite in direct tensor notations

$$
\begin{array}{ll}
\llbracket \boldsymbol{\nabla} \otimes \boldsymbol{\nabla} \otimes \mathbf{u} \rrbracket=\mathbf{n} \otimes \mathbf{n} \otimes \mathbf{A}, & \llbracket \boldsymbol{\nabla} \otimes \boldsymbol{\nabla} \otimes \boldsymbol{\phi} \rrbracket=\mathbf{n} \otimes \mathbf{n} \otimes \mathbf{S}, \\
\llbracket \boldsymbol{\nabla} \otimes \dot{\mathbf{u}} \rrbracket=-G \mathbf{n} \otimes \mathbf{A}, & \llbracket \boldsymbol{\nabla} \otimes \dot{\boldsymbol{\phi}} \rrbracket=-G \mathbf{n} \otimes \mathbf{S}, \\
\llbracket \ddot{\mathbf{u}} \rrbracket=G^{2} \mathbf{A}, & \llbracket \ddot{\boldsymbol{\phi}} \rrbracket=G^{2} \mathbf{S},
\end{array}
$$

where square brackets denote jump across surface of weak discontinuities. $B, \mathbf{A}, \mathbf{S}$ are fields defined on this surface, and the equalities $B=0, \mathbf{A}=\mathbf{0}, \mathbf{S}=\mathbf{0}$ cannot be satisfied simultaneously at any point of the surface, if the surface is indeed the surface of weak discontinuities. Equations (14) and (16) give the following relations between the jumps of partial derivatives of the second order across the wave surface:

$$
\left\{\begin{array}{l}
\left(\rho G^{2}-(\mu+\eta)\right) \mathbf{A}-(\lambda+\mu-\eta) \mathbf{n}(\mathbf{n} \cdot \mathbf{A})=\mathbf{0}, \\
\left(\mathfrak{J} G^{2}-(\gamma+\varepsilon)\right) \mathbf{S}-(\beta+\gamma-\varepsilon) \mathbf{n}(\mathbf{n} \cdot \mathbf{S})=\mathbf{0}, \\
B+\frac{\alpha G}{\Lambda_{*}} \mathbf{n} \cdot \mathbf{A}+\frac{\varsigma G}{\Lambda_{*}} \mathbf{n} \cdot \mathbf{S}=0 .
\end{array}\right.
$$

The polarization vectors of the wave $\mathbf{A}, \mathbf{S}$ can be splited into a sum of projections onto the tangent plane and on the normal direction to the wave surface:

$$
\begin{array}{cl}
\mathbf{A}=A_{\perp} \boldsymbol{\tau}+A_{\|} \mathbf{n}, & \mathbf{S}=S_{\perp} \tau+S_{\|} \mathbf{n}, \\
A_{\perp}=\mathbf{A} \cdot \boldsymbol{\tau}, & A_{\|}=\mathbf{A} \cdot \mathbf{n}, \\
S_{\perp}=\mathbf{S} \cdot \boldsymbol{\tau}, & S_{\|}=\mathbf{S} \cdot \mathbf{n},
\end{array}
$$

where $\boldsymbol{\tau}$ is the tangential unit vector and $\mathbf{n}$ is the normal unit one of the wave surface respectively. Taking account of equations (18) the system (17) is transformed into

$$
\left\{\begin{array}{l}
\left(\rho G^{2}-(\mu+\eta)\right)\left(A_{\perp} \boldsymbol{\tau}+A_{\|} \mathbf{n}\right)-(\lambda+\mu-\eta) A_{\|} \mathbf{n}=\mathbf{0}, \\
\left(\mathfrak{J} G^{2}-(\gamma+\varepsilon)\right)\left(S_{\perp} \boldsymbol{\tau}+S_{\|} \mathbf{n}\right)-(\beta+\gamma-\varepsilon) S_{\|} \mathbf{n}=\mathbf{0}, \\
B+\frac{\alpha G}{\Lambda_{*}} A_{\|}+\frac{\varsigma G}{\Lambda_{*}} S_{\|}=0 .
\end{array}\right.
$$


After rearrangements in equations (19) in view of (18) the following system is derived:

$$
\left\{\begin{array}{l}
\left(\rho G^{2}-(\mu+\eta)\right) A_{\perp} \boldsymbol{\tau}+\left(\rho G^{2}-(\lambda+2 \mu)\right) A_{\|} \mathbf{n}=\mathbf{0}, \\
\left(\mathfrak{J} G^{2}-(\gamma+\varepsilon)\right) S_{\perp} \boldsymbol{\tau}+\left(\mathfrak{J} G^{2}-(\gamma+2 \beta)\right) S_{\|} \mathbf{n}=\mathbf{0}, \\
B+\frac{\alpha G}{\Lambda_{*}} A_{\|}+\frac{\varsigma G}{\Lambda_{*}} S_{\|}=0 .
\end{array}\right.
$$

The third equation in (20) allows us to couple a weak discontinuity of temperature with a normal projection of weak discontinuities of translational displacements and microrotations by

$$
B=-\frac{\alpha G}{\Lambda_{*}} A_{\|}-\frac{\varsigma G}{\Lambda_{*}} S_{\|}
$$

This new equation is obtained by restrictions $\varsigma \neq 0$.

By the aid of orthogonality of the vectors $\boldsymbol{\tau}$ and $\mathbf{n}$ the following equations are obtained

$$
\left\{\begin{array} { l } 
{ ( \rho G ^ { 2 } - ( \mu + \eta ) ) A _ { \perp } = 0 , } \\
{ ( \rho G ^ { 2 } - ( \lambda + 2 \mu ) ) A _ { \| } = 0 , }
\end{array} \quad \left\{\begin{array}{l}
\left(\mathfrak{J} G^{2}-(\gamma+\varepsilon)\right) S_{\perp}=0, \\
\left(\mathfrak{J} G^{2}-(\gamma+2 \beta)\right) S_{\|}=0 .
\end{array}\right.\right.
$$

\section{A CLASSIFICATION OF WEAK DISCONTINUITIES IN THE MPTE-I CONTINUUM}

The 16 cases can be discriminated according to (5). These cases are gathered into the following Table. We proceed by considering the discriminated cases separately.

\begin{tabular}{|l|l|l|l|l|l|}
\hline Cases & \multicolumn{2}{|l|}{$\begin{array}{l}\text { Intensity vectors projections of } \\
\text { weak discontinuities of trans- } \\
\text { lational displacements }\end{array}$} & \multicolumn{2}{l|}{$\begin{array}{l}\text { Intensity vectors projections } \\
\text { of weak discontinuity of mic- } \\
\text { rorotations }\end{array}$} & $\begin{array}{l}\text { Intensity of weak discon- } \\
\text { tinuity of temperature }\end{array}$ \\
\hline I & $A_{\|}=0$ & $A_{\perp}=0$ & $S_{\|}=0$ & $S_{\perp}=0$ & $B=0$ \\
\hline II & $A_{\|}=0$ & $A_{\perp} \neq 0$ & $S_{\|}=0$ & $S_{\perp}=0$ & $B=0$ \\
\hline III & $A_{\|} \neq 0$ & $A_{\perp}=0$ & $S_{\|}=0$ & $S_{\perp}=0$ & $B=-\frac{\alpha G}{\Lambda_{*}} A_{\|}$ \\
\hline $\mathrm{IV}$ & $A_{\|}=0$ & $A_{\perp}=0$ & $S_{\|}=0$ & $S_{\perp} \neq 0$ & $B=0$ \\
\hline $\mathrm{V}$ & $A_{\|}=0$ & $A_{\perp}=0$ & $S_{\|} \neq 0$ & $S_{\perp}=0$ & $B=-\frac{\varsigma G}{\Lambda_{*}} S_{\|}$ \\
\hline $\mathrm{VI}$ & $A_{\|}=0$ & $A_{\perp} \neq 0$ & $S_{\|}=0$ & $S_{\perp} \neq 0$ & $B=-\frac{\alpha G}{\Lambda_{*}} A_{\|}-\frac{\varsigma G}{\Lambda_{*}} S_{\|}$ \\
\hline $\mathrm{VII}$ & $A_{\|} \neq 0$ & $A_{\perp}=0$ & $S_{\|} \neq 0$ & $S_{\perp}=0$ & $B=0$ \\
\hline $\mathrm{VIII}$ & $A_{\|} \neq 0$ & $A_{\perp} \neq 0$ & $S_{\|}=0$ & $S_{\perp}=0$ & $B=-\frac{\alpha G}{\Lambda_{*}} A_{\|}$ \\
\hline $\mathrm{IX}$ & $A_{\|}=0$ & $A_{\perp}=0$ & $S_{\|} \neq 0$ & $S_{\perp} \neq 0$ & $B=-\frac{\varsigma G}{\Lambda_{*}} S_{\|}$ \\
\hline $\mathrm{X}$ & $A_{\|} \neq 0$ & $A_{\perp}=0$ & $S_{\|}=0$ & $S_{\perp} \neq 0$ & $B=-\frac{\alpha G}{\Lambda_{*}} A_{\|}$ \\
\hline $\mathrm{XI}$ & $A_{\|}=0$ & $A_{\perp} \neq 0$ & $S_{\|}=0$ & $S_{\perp} \neq 0$ & $B=0$ \\
\hline $\mathrm{XII}$ & $A_{\|} \neq 0$ & $A_{\perp}=0$ & $S_{\|} \neq 0$ & $S_{\perp} \neq 0$ & $B=-\frac{\alpha G}{\Lambda_{*}} A_{\|}-\frac{\varsigma G}{\Lambda_{*}} S_{\|}$ \\
\hline $\mathrm{XIII}$ & $A_{\|}=0$ & $A_{\perp} \neq 0$ & $S_{\|} \neq 0$ & $S_{\perp} \neq 0$ & $B=-\frac{\varsigma G}{\Lambda_{*}} S_{\|}$ \\
\hline $\mathrm{XIV}$ & $A_{\|} \neq 0$ & $A_{\perp} \neq 0$ & $S_{\|} \neq 0$ & $S_{\perp}=0$ & $B=-\frac{\alpha G}{\Lambda_{*}} A_{\|}-\frac{\varsigma G}{\Lambda_{*}} S_{\|}$ \\
\hline $\mathrm{XV}$ & $A_{\|} \neq 0$ & $A_{\perp} \neq 0$ & $S_{\|}=0$ & $S_{\perp} \neq 0$ & $B=-\frac{\alpha G}{\Lambda_{*}} A_{\|}$ \\
\hline $\mathrm{XVI}$ & $A_{\|} \neq 0$ & $A_{\perp} \neq 0$ & $S_{\|} \neq 0$ & $S_{\perp} \neq 0$ & $B=-\frac{\alpha G}{\Lambda_{*}} A_{\|}-\frac{\varsigma G}{\Lambda_{*}} S_{\|}$ \\
\hline
\end{tabular}


Evidently in the first case $\mathbf{A}=\mathbf{0}, \mathbf{S}=\mathbf{0}$ and returning to (17) the scalar equation in (17) is satisfied identically, so the surface $\Sigma$ is actually not a surface of weak discontinuities.

In the second case, the first equation of system (21) is valid only on a wave surface propagating with normal velocity

$$
G=c_{\|},
$$

where

$$
c_{\|}=\sqrt{\frac{\lambda+2 \mu}{\rho}} .
$$

In this case the normal velocity of a weak discontinuity surface propagation $G,(22)$ is the well known velocity of longitudinal elastic wave $c_{\|}$. In addition, if wave surface is bypassed, then the derivative of temperature field is broke according to the third equation in (20):

$$
B=-\frac{\alpha G}{\Lambda_{*}} A_{\|} .
$$

In the third case a weak discontinuity of translational displacements exists only on the surface propagating with the velocity

$$
G=c_{\perp}^{\mu},
$$

where

$$
c_{\perp}^{\mu}=\sqrt{\frac{\mu+\eta}{\rho}} .
$$

It can be elucidated that the velocity $G(23)$ exactly coincides with the one of transverse elastic wave if the constitutive micropolar constant $\eta$ equals to zero $c_{\perp}=\sqrt{\mu / \rho}$.

The fourth case implies existence of a weak discontinuity of microrotation. Then the third equation of system (20) is satisfied only on the surface of weak discontinuities propagating with normal velocity

$$
G=c_{\|}^{\mu \mu},
$$

where

$$
c_{\|}^{\mu \mu}=\sqrt{\frac{\beta+2 \gamma}{\mathfrak{J}}}
$$

is the wave velocity of torsion. As in the previous case, a weak discontinuity of microrotation is associated with a weak discontinuity of a temperature field according to third equation of system (20):

$$
B=-\frac{\varsigma G}{\Lambda_{*}} S_{\|} .
$$

Thus, the constitutive constants $\alpha, \varsigma$ characterize the intensity of thermal weak discontinuity.

In the fifth case, the fourth equation of the system (20) allows to compute the propagation velocity of a weak discontinuities of microrotation

$$
G=c_{\perp}^{\mu \mu},
$$

where

$$
c_{\perp}^{\mu \mu}=\sqrt{\frac{\gamma+\varepsilon}{\mathfrak{J}}} .
$$

Focus attention that a weak discontinuity of temperature is not associated with the tangential projections of polarization vectors of weak discontinuities $A_{\perp}$ and $S_{\perp}$.

In other cases (from the VI to the XVI) the propagation of wave surfaces of weak discontinuities displacements, microrotations and temperature is impossible if the constitutive characteristic of the type-I micropolar thermoelastic continuum does not satisfied certain limitations as determined by (21).

In a 6 -th case the factors at $A_{\|}$and $S_{\|}$should be vanished simultaneously, it is impossible if $c_{\|} \neq c_{\|}^{\mu \mu}$. Clearly, then the considered surface will not be a wave one. If the continuum can be described constitutive equation of $c_{\|}=c_{\|}^{\mu \mu}$, then the wave surface is a wave propagating with a velocity

$$
G=c_{\|}=c_{\|}^{\mu \mu},
$$


and weak discontinuity of temperature field is out of condition

$$
B=-\frac{\alpha G}{\Lambda_{*}} A_{\|}-\frac{\varsigma G}{\Lambda_{*}} S_{\|} .
$$

The above Eqs (24) implies a possibility of nondissipative propagation of longitudinal waves when $B=0$, i.e.

$$
\frac{\alpha}{\varsigma}=-\frac{S_{\|}}{A_{\|}}
$$

In the seventh case, the factors at $A_{\perp}$ and $S_{\perp}$ can not be equal to zero simultaneously, if $c_{\perp}^{\mu} \neq c_{\perp}^{\mu \mu}$. In contrary, if the continuum characterizes matching of the transverse waves velocities $c_{\perp}^{\mu}=c_{\perp}^{\mu \mu}$, then the velocity of propagation of a wave surface is equal

$$
G=c_{\perp}^{\mu}=c_{\perp}^{\mu \mu}
$$

Weak discontinuity of temperature field is again identified from the condition (24) and it disappears in the absence of normal polarization vectors projections.

Underline that in the 3-th and 5-th cases the surface of weak discontinuities in MPTE-I continuum can propagated along with the absence of weak discontinuities of temperature field, which means nondissipative mechanism for the such surfaces propagating.

\section{ACTION. COMPATIBILITY CONDITIONS FOR JUMPS}

A field theory formalism involves mathematical description of physical fields by integral action functional. A general form of action within a variable domain of 4-spacetime with the elementary volume of $d^{4} X=d X^{1} d X^{2} d X^{3} d X^{4}$ is

$$
\mathscr{I}=\int \mathscr{L}\left(X^{\beta}, \varphi^{k}, \partial_{\alpha} \varphi^{k}\right) d^{4} X
$$

where $\varphi^{k}$ is the physical fields array, $\mathscr{L}$ - the Lagrangian density.

The least action principle states that the actual field is realized in the spacetime in a way that the action of (1) is minimum, i. e. for any admissible variations of physical fields $\varphi^{k}$ and non-variable coordinates $X^{\beta}$ are $\delta \mathscr{I}=0$. Then the classical Euler-Lagrange equations are held:

$$
\mathscr{E}_{k}(\mathscr{L})=\frac{\partial \mathscr{L}}{\partial \varphi^{k}}-\partial_{\alpha} \frac{\partial \mathscr{L}}{\partial\left(\partial_{\alpha} \varphi^{k}\right)}=0 .
$$

In general, a conservation law has the following form

$$
\partial_{\beta} J^{\beta}=0,
$$

where the vector $J^{\beta}$ is the vector 4 -current. By finite variation $\delta^{\nabla}=\delta / \varepsilon$ the 4 -current can be obtained as

$$
J^{\beta}=\frac{\partial \mathscr{L}}{\partial\left(\partial_{\beta} \varphi^{k}\right)} \delta^{\nabla} \varphi^{k}+\left(\mathscr{L} \delta_{\alpha}^{\beta}-\left(\partial_{\alpha} \varphi^{k}\right) \frac{\partial \mathscr{L}}{\partial\left(\partial_{\beta} \varphi^{k}\right)}\right) \delta^{\nabla} X^{\alpha},
$$

if the variational symmetries of the action are known.

The finite variation of the action is (see [7])

$$
\delta^{\nabla} \mathscr{I}=\int\left(\partial_{\beta} J^{\beta}\right) d^{4} X
$$

Assuming the temperature field is continuous and temperature gradient of the first order can be discontinuous by passing through some bilateral surface $\Sigma^{ \pm}$propagating with the normal velocity $G$ and normal unit 4 -vector $\mathscr{N}_{\beta}$ in 4 -spacetime.

We replace the integral over 4 -volume in equation (25) on sum of surface integrals. Then only two surface integrals over surface $\Sigma$ are remained when the variations $\delta^{\nabla} \varphi^{k}$ and $\delta^{\nabla} X^{\beta}$ are fixed on the outer boundary of the field:

$$
\delta^{\nabla} \mathscr{I}=\int_{\Sigma^{+}}\left(J^{\beta} \mathscr{N}_{\beta}\right)^{+} d \Sigma-\int_{\Sigma^{-}}\left(J^{\beta} \mathscr{N}_{\beta}\right)^{-} d \Sigma=\int_{\Sigma}\left[J^{\beta}\right] \mathscr{N}_{\beta} d \Sigma .
$$

Hereafter square brackets denote 4-jumps. 
The equation $\delta \mathrm{Im}=0$ is valid for the actual field and a variations of $\delta \varphi^{k}$ and $\delta X^{\beta}$ are continuous in passing through the surface $\Sigma$. Therefore following 4-covariant compatibility equations for strong discontinuities is obtained from (26):

$$
\mathscr{N}_{\beta}\left[-\frac{\partial \mathscr{L}}{\partial\left(\partial_{\beta} \varphi^{k}\right)}\right]=0, \quad \mathscr{N}_{\beta}\left[\mathscr{L} \delta_{\alpha}^{\beta}-\left(\partial_{\alpha} \varphi^{k}\right) \frac{\partial \mathscr{L}}{\partial\left(\partial_{\beta} \varphi^{k}\right)}\right]=0 .
$$

One can see, that the compatibility conditions on strong discontinuities surfaces contain the jumps of the energy-momentum 4-tensor and the Piola-Kirchhoff 4-tensor

$$
S_{4}^{\beta \cdot k}=-\frac{\partial \mathscr{L}}{\partial\left(\partial_{\beta} \varphi^{k}\right)}, \quad T_{\cdot \alpha}^{\beta \cdot}=\mathscr{L} \delta_{\alpha}^{\beta}-\left(\partial_{\alpha} \varphi^{k}\right) \frac{\partial \mathscr{L}}{\partial\left(\partial_{\beta} \varphi^{k}\right)} .
$$

The compatibility conditions of jumps of the energy-momentum 4-tensor in view of (28) is rewritten in form

$$
\mathscr{N}_{\beta}\left[T_{\cdot \alpha}^{\beta \cdot}\right]=[\mathscr{L}] \mathscr{N}_{\alpha}+\left[\partial_{\alpha} \varphi^{k} S_{4}^{\beta \cdot k}\right] \mathscr{N}_{\beta}=0 .
$$

Relations (29) can be transformed by the compatibility conditions of the strong discontinuities of the Piola - Kirchhoff 4-tensor into

$$
[\mathscr{L}] \mathscr{N}_{\alpha}+\left[\partial_{\alpha} \varphi^{k}\right] S_{4}^{\beta \cdot k} \mathscr{N}_{\beta}=0 .
$$

The only significant equation from the compatibility conditions for jumps of the energy-momentum 4tensor by using the Hadamard - Thomas geometric first order compatibility conditions [8] $\left[\partial_{\alpha} \varphi^{k}\right]=\mathscr{N}_{\alpha} \mathscr{F}^{k}$ is obtained

$$
[\mathscr{L}]+S_{4}^{\beta} \cdot \mathscr{N}_{\beta} \mathscr{F}^{k}=0 .
$$

The three-dimensional form of the compatibility conditions on the surface of strong discontinuity of the field is derived from the resulting 4-covariant form (27), (30):

$$
\begin{gathered}
\llbracket \mathscr{L} \rrbracket+\left(-G S_{4}^{4 \cdot k}+n_{\mu} S_{4}^{\mu \cdot}\right)\left(-G \llbracket \partial_{4} \varphi^{k} \rrbracket+n_{\mu} \llbracket \partial_{\mu} \varphi^{k} \rrbracket\right)=0 ; \\
-G \llbracket S_{4}^{4 \cdot k} \rrbracket+n_{\mu} \llbracket S_{4}^{\mu \cdot k} \rrbracket=0 \quad(\lambda, \mu=1,2,3) .
\end{gathered}
$$

Hereafter $n_{\mu}$ stand for normal unit 3-vector.

The compatibility conditions for strong discontinuities are complemented by well known threedimensional geometrical and kinematic Hadamard - Thomas compatibility conditions of the first and the second order [8] valid for an arbitrary field $\varphi^{k}$. Those are also due to Rankine and Hugoniot $[12,13]$.

\section{ACTION FOR MPTE-II CONTINUA}

The theory GNII is the only thermodynamically correct theory which satisfies the principles listed in Sec. 1. The action taking into account of the polar microstructure can be adopted in the following form [7]

$$
\mathscr{L}=\int \mathscr{L}\left(X^{\alpha}, x^{j}, \underset{\mathfrak{a}}{d^{j}}, \vartheta, \partial_{4} x^{j}, \partial_{4} d_{\mathfrak{a}}^{j}, \partial_{4} \vartheta, \partial_{\beta} x^{j}, \underset{\mathfrak{a}}{\partial_{\beta} d^{j}}, \partial_{\beta} \vartheta\right) d X^{1} d X^{2} d X^{3} d X^{4}
$$

where $X^{\alpha}(\alpha=1,2,3)$ are the Lagrangian coordinates; $x^{j}(j=1,2,3)$ are the Eulerian coordinates; $d_{\mathfrak{a}}^{j}(\mathfrak{a}=1,2,3)$ are micropolar directors associated with microvolume; $\vartheta$ is the thermal displacement field.

Action density (32) we define in the form

$$
\mathscr{L}=\frac{1}{2}\left(\partial_{4} x^{k}\right) \rho_{k j}\left(\partial_{4} x^{j}\right)+\frac{1}{2}\left(\partial_{4} d_{\mathfrak{a}}^{i}\right) \stackrel{\mathfrak{I}}{\mathfrak{I}}_{i j}\left(\partial_{4} d_{\mathfrak{b}}^{j}\right)-\psi\left(X^{\alpha}, x^{j}, d_{\mathfrak{a}}^{j}, \vartheta, \partial_{4} \vartheta, \partial_{\alpha} x^{j}, \partial_{\alpha} d_{\mathfrak{a}}^{j}, \partial_{\alpha} \vartheta\right),
$$

wherein $\stackrel{\mathfrak{a} \mathfrak{b}}{\mathfrak{I}}_{i j}$ - the microinertion tensor; $\rho_{i j}$ - the mass density tensor; $\psi-$ volume density of the Helmholtz's free energy. For tensors $\stackrel{\mathfrak{a}}{\mathfrak{I}}_{i j}$ and $\rho_{i j}$ the symmetry conditions $\rho_{i j}=\rho_{j i}, \stackrel{\mathfrak{a}}{\mathfrak{I}}_{i j}=\stackrel{\mathfrak{a}}{\mathfrak{l}}_{j i}$ are stated.

The field equations in this case read:

$$
\partial_{\alpha} S_{\cdot j}^{\alpha \cdot}-\partial_{4} P_{j}=-\frac{\partial \mathscr{L}}{\partial x^{j}} \quad(\alpha=1,2,3, \quad j=1,2,3),
$$




$$
\begin{gathered}
\partial_{\alpha} \mathscr{\mathscr { M }}_{\cdot j}^{\alpha \cdot}+\mathscr{\mathscr { A }}_{j}-\partial_{4}\left(\stackrel{\mathfrak{Q}}{\mathscr{Q}}_{j}\right)=0 \quad(\mathfrak{a}=1,2,3, \quad \alpha=1,2,3, \quad j=1,2,3), \\
\partial_{\alpha} j_{\mathrm{R}}^{\alpha}+\partial_{4} s=\frac{\partial \mathscr{L}}{\partial \vartheta} \quad(\alpha=1,2,3),
\end{gathered}
$$

and are supplemented by the constitutive equations:

$$
\begin{gathered}
S_{\cdot j}^{\alpha \cdot}=-\frac{\partial \mathscr{L}}{\partial\left(\partial_{\alpha} x^{j}\right)}, \quad \stackrel{\mathfrak{M}}{\cdot j}_{\cdot j}^{\alpha}=-\frac{\partial \mathscr{L}}{\partial\left(\partial_{\alpha} d_{\mathfrak{a}}^{j}\right)}, \quad \mathscr{A}_{j}=\frac{\partial \mathscr{L}}{\partial d_{\mathfrak{a}}^{j}}, \\
P_{j}=\frac{\partial \mathscr{L}}{\partial\left(\partial_{4} x^{j}\right)}, \quad \stackrel{\mathfrak{a}}{\mathscr{Q}}_{j}=\frac{\partial \mathscr{L}}{\partial\left(\partial_{4} d_{\mathfrak{a}}^{j}\right)}, \quad s=\frac{\partial \mathscr{L}}{\partial\left(\partial_{4} \vartheta\right)}, \quad j_{\mathrm{R}}^{\alpha}=\frac{\partial \mathscr{L}}{\partial\left(\partial_{\alpha} \vartheta\right)} .
\end{gathered}
$$

Compatibility conditions on strong discontinuity surface propagating in MPTE-II continuum, according eqs. (30), (31), take the forms:

$$
\begin{aligned}
& \frac{1}{2} \llbracket \partial_{4} d_{\mathfrak{a}}^{\stackrel{i}{\mathfrak{a}}_{\mathfrak{\mathfrak { I }}}^{\mathfrak{a} \mathfrak{b}}}{ }_{i j} \partial_{4} d_{\mathfrak{b}}^{j} \rrbracket+\left(G \stackrel{\mathfrak{a} \mathfrak{b}}{\mathfrak{I}} l k \partial_{4} d_{\mathfrak{a}}^{l}-n_{\mu} \stackrel{\mathfrak{M}}{\mathscr{M}}_{\cdot k}^{\mu \cdot}\right)\left(G \llbracket \partial_{\mathfrak{a}} d^{k} \rrbracket-n_{\mu} \llbracket \partial_{\mu} d_{\mathfrak{a}}^{k} \rrbracket\right)+\frac{1}{2} \llbracket \partial_{4} x^{k} \rho_{k j} \partial_{4} x^{j} \rrbracket+ \\
& +\left(G \rho_{l k} \partial_{4} x^{l}-n_{\mu} S_{\cdot k}^{\mu \cdot}\right)\left(G \llbracket \partial_{4} x^{k} \rrbracket-n_{\mu} \llbracket \partial_{\mu} x^{k} \rrbracket\right)-\llbracket \psi \rrbracket+\left(G s-n_{\mu} j_{\mathrm{R}}^{\mu}\right)\left(G \llbracket \partial_{4} \vartheta \rrbracket-n_{\mu} \llbracket \partial_{\mu} \vartheta \rrbracket\right)=0, \\
& G \rho_{k l} \llbracket \partial_{4} x^{k} \rrbracket=n_{\mu} \llbracket S_{\cdot l}^{\mu \cdot} \rrbracket, \quad G \stackrel{\mathfrak{I}}{\mathfrak{I}}_{k l}^{\mathfrak{a}} \llbracket \partial_{4} d_{\mathfrak{a}}^{k} \rrbracket=n_{\mu} \llbracket \mathscr{\mathscr { M }}_{\cdot l}^{\mu \cdot} \rrbracket, \quad G \llbracket s \rrbracket=n_{\mu} \llbracket j_{\mathrm{R}}^{\mu} \rrbracket, \\
& \llbracket \mathscr{L} \rrbracket=\frac{1}{2} \llbracket \partial_{4} x^{k} \rho_{k j} \partial_{4} x^{j} \rrbracket+\frac{1}{2} \llbracket \partial_{4} d_{\mathfrak{a}}^{i} \stackrel{\mathfrak{a}}{\mathfrak{I} \mathfrak{b}}_{i j} \partial_{4} d_{\mathfrak{b}}^{j} \rrbracket-\llbracket \psi \rrbracket \quad(j, k, l, \lambda, \mu=1,2,3) .
\end{aligned}
$$

In the case of the propagating surface of strong discontinuity through unperturbed continuum the first of the compatibility equations (33) can be transformed to

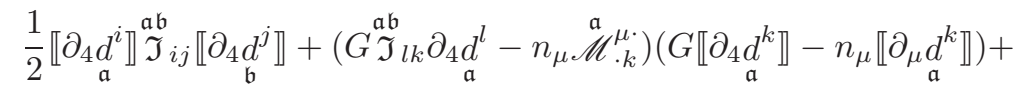

$$
\begin{aligned}
& +\frac{1}{2} \llbracket \partial_{4} x^{k} \rrbracket \rho_{k j} \llbracket \partial_{4} x^{j} \rrbracket+\left(G \rho_{l k} \partial_{4} x^{l}-n_{\mu} S_{\cdot k}^{\mu \cdot}\right)\left(G \llbracket \partial_{4} x^{k} \rrbracket-n_{\mu} \llbracket \partial_{\mu} x^{k} \rrbracket\right)- \\
& -\llbracket \psi \rrbracket+\left(G s-n_{\mu} j_{\mathrm{R}}^{\mu}\right)\left(G \llbracket \partial_{4} \vartheta \rrbracket-n_{\mu} \llbracket \partial_{\mu} \vartheta \rrbracket\right)=0 \quad(j, k, l, \lambda, \mu=1,2,3) .
\end{aligned}
$$

The present work was partially supported by the Russian Foundation for Basic Research (project no. 13-01-00139 "Hyperbolic thermal waves in solids with microstructure") and the Ministry of Education and Science of Russia Federation grant given to Samara State Technical University (project no. $16.2518 .2014 / \mathrm{K})$.

\section{References}

1. Cosserat E., Cosserat F. Theories of Deformable Bodies. Paris, Scientific Library A. Hermann et Fils, 1909, $242 \mathrm{p}$.

2. Green A. E., Naghdi P. M. On Undamped Heat Waves in an Elastic Solid. J. Therm. Stress, 1992, vol. 15, pp. 253-264.

3. Green A. E., Naghdi P. M. Thermoelasticity without Energy Dissipation. J. Elasticity, 1993, vol. 31, pp. 189208.

4. Radayev Yu. N., Semenov D. A. Harmonic Coupled CTE-Thermoelastic Waves in a Free Cylindrical Waveguide. Vestn. Samar. Gos. Univ. Natural sciences ser., 2008, no. 8/1(67), pp. 411-459 (in Russian).

5. Kovalev V. A., Radayev Yu. N., Semenov D. A. Coupled Dynamic Problems in Hyperbolic Thermoelasticity. Izv. Saratov Univ. (N.S.), Ser. Math. Mech. Inform., 2009, vol. 10, iss. 4, pt. 2, pp. 94-128 (in Russian).

6. Kovalev V. A., Radayev Yu. N. Wavenumbers of Plane
GNIII-Thermoelastic Waves and Inequality, Providing Their Normality. Izv. Saratov Univ. (N. S.), Ser. Math. Mech. Inform., 2010, vol. 10, iss. 3, pp. 46-53 (in Russian).

7. Kovalev V. A., Radayev Yu. N. Wave Problems of Field Theory and Thermomechanics. Saratov, Saratov. Univ. Press, 2010, 328 p. (in Russian).

8. Thomas T. Y. Plastic Flow and Fracture in Solids. New York, Academic Press, 1961, 271 p.

9. Nowacki W. Theory of Asymmetric Elasticity. Oxford, Pergamon Press, 1986, 384 p.

10. Mindlin R. D., Tiersten H. F. Effects of couplestresses in linear elasticity. Arch. for Rat. Mech. and Anal., 1962, vol. 11, iss. 1, pp. 415-448.

11. Eringen A. C. Microcontinuum field theories. Vol. 1. Foundations and Solids. Berlin, Heidelberg, New York, Springer, 1999, $325 \mathrm{p}$.

12. Rankine W. J. M. On the thermodynamic theory 
13. Hugoniot P. H. Sur la propagation du mouvement

of waves of finite longitudinal disturbance. Proc. of the Royal Society of London. London, The Royal Society, 1870, vol. 18, pp. $80-83$. dans les corps et specialement dans les gaz parfaits.

J. Ecole Polytechnique, 1887, vol. CLVII, pp. 3-98.

УДК 539.3

\title{
О слабых разрывах и уравнениях скачков на волновых поверхностях в микрополярных термоупругих континуумах
}

\author{
В. А. Ковалев ${ }^{1}$, Е. В. Мурашкин ${ }^{2}$ Ю. Н. Радаев ${ }^{3}$ \\ ${ }^{1}$ Доктор фризико-математических наук, профрессор кафедры управления проектами и инвестициями, Московский городской \\ университет управления Правительства Mockвы, vlad_koval@mail.ru \\ ${ }^{2}$ Кандидат сризико-математических наук, доцент, Национальный исследовательский ядерный университет МИФИ, Москва, \\ murashkin@ipmnet.ru, evmurashkin@gmail.com \\ ${ }^{3}$ Доктор фризико-математических наук, просрессор, ведущий научный сотрудник, Институт проблем механики \\ им. А. Ю. Ишлинского РАН, Москва, radayev@ipmnet.ru, y.radayev@gmail.com
}

\begin{abstract}
Настоящее исследование посвящено проблеме распространения поверхностей сильных и слабых разрывов поступательных перемещений, микровращений и температуры в микрополярных (МП) термоупругих (ТЕ) континуумах. В первой части статьи обсуждаются проблемы распространения слабых разрывов в МРТЕ континуумах первого типа. Геометрические и кинематические условия совместимости Адамара и Томаса используются для изучения возможных волновых поверхностей слабых разрывов. Слабые разрывы классифрицируются в соответствии с пространственной ориентировкой векторов поляризации разрывов (DPVs). Показано, что поверхности слабых разрывов могут распространяться без слабых разрывов температурного поля. Вторая часть работы посвящена распространению поверхностей сильных разрывов полевых переменных в MPTE континуумах второго типа. Определяющие соотношения для гиперболических термоупругих микрополярных континуумов второго типа получены с помощью фрормализма теории поля. Специальная форма первой вариации интеграла действия позволяет получить 4-ковариантные условия скачков на волновых поверхностях. Трехмерная срорма условий скачков на поверхности сильного разрыва поля выводится из ее четырехмерной ковариантной фрормы.
\end{abstract}

Ключевые слова: микрополярная термоупругость, континуум первого типа, континуум второго типа, слабый разрыв, сильный разрыв, ударная волна, продольная волна, поперечная волна, условие совместимости, скачок.

Работа выполнена при частичной финансовой поддержке РФФИ (проект № 13-01-00139 «Гиперболические тепловые волны в твердых телах с микроструктурой») и Минобрнауки РФ в рамках проектной части гос. задания ФГБОУ ВПО «СамГТУ» (проект № 16.2518.2014/(K)).

\section{Библиографический список}

1. Cosserat E. et F. Theorie des corps deformables. Paris : Librairie Scientifique A. Hermann et Fils, 1909. 226 p.

2. Green A. E., Naghdi P. M. On undamped heat waves in an elastic solid // J. Therm. Stress. 1992. Vol. 15. P. 253-264.

3. Green A. E., Naghdi P. M. Thermoelasticity without energy dissipation // J. Elasticity. 1993. Vol. 31. P. 189208.

4. Радаев Ю. Н., Семенов Д. А. Гармонические связанные СТЕ-термоупругие волны в свободном цилиндрическом волноводе // Вестн. Самар. гос. ун-та. Естественнонауч. сер. 2008. № 8/1(67). С. 411-459.

5. Ковалев В. А., Радаев Ю. Н., Семенов Д. А. Связанные динамические задачи гиперболической термоупругости // Изв. Сарат. ун-та. Нов. сер. Сер. Математика. Механика. Информатика. 2009. Т. 9, вып. 4, ч. 2. C. $94-128$.

6. Ковалев В. А., Радаев Ю. Н. Волновые числа плоских GNIII-термоупругих волн и неравенства, обеспечивающие их нормальность // Изв. Сарат. ун-та. Нов. сер. Сер. Математика. Механика. Информатика. 2010. Т. 10, вып. 3. С. 46-53.
7. Ковалев В. А., Радаев Ю. Н. Волновые задачи теории поля и термомеханика. Саратов : Изд-во Сарат. ун-та, 2010. 328 c

8. Thomas T. Y. Plastic Flow and Fracture in Solids. N. Y. : Academic Press, 1961. 271 p.

9. Nowacki W. Theory of Asymmetric Elasticity. Oxford: Pergamon Press, 1986. 384 p.

10. Mindlin R. D., Tiersten H. F. Effects of couplestresses in linear elasticity // Arch. for Rat. Mech. and Anal. 1962. Vol. 11, iss. 1. P 415-448.

11. Eringen A. C. Microcontinuum field theories. Vol. 1. Foundations and Solids. Berlin ; Heidelberg ; N. Y. : Springer, 1999. 325 p.

12. Rankine W. J. M. On the thermodynamic theory of waves of finite longitudinal disturbance // Proc. of the Royal Society of London. London : The Royal Society, 1870. Vol. 18. P. 80-83.

13. Hugoniot $P$. H. Sur la propagation du mouvement dans les corps et specialement dans les gaz parfaits // J. Ecole Polytechnique. 1887. Vol. CLVII. P. 3-98. 